\title{
Effects of ultrasonic waves on eggshell strength and hatchability of layer-type breeder eggs
}

\author{
T.M. Shafey ${ }^{\#}$, E.O.S. Hussein \& H.A. AL-Batshan \\ Department of Animal Production, College of Food and Agriculture Sciences, King Saud University, \\ Riyadh, Saudi Arabia
}

(Received 5 October 2012; Accepted 14 January 2013; First published online13 March 2013)

Copyright resides with the authors in terms of the Creative Commons Attribution 2.5 South African Licence.

See: http://creativecommons.org/licenses/by/2.5/za

Condition of use: The user may copy, distribute, transmit and adapt the work, but must recognise the authors and the South African Journal of Animal Science.

\begin{abstract}
Two trials were conducted to investigate the effects of exposing layer-type breeder eggs before incubation to ultrasonic waves (ULT). Eggs were subjected to ULT of 117 volts at $40 \mathrm{kHz}$ for up to 15 minutes. Eggshell breaking force (EBF), hatchability and chick hatching weight (CHW) of Balady breeder eggs (Trial 1), and egg weight loss, embryo weight, hatchability and CHW of Leghorn hen eggs (Trial 2) were measured. In Trial 1 the eggs were subjected to seven treatments: non-dipped (control), and dipped for 5, 10 and 15 minutes in a water bath (W5, W10 and W15) or a ULT bath (ULT5, ULT10 and ULT15). In Trial 2 the eggs were subjected to four treatments, a control (ULT0) and the ultrasonic treatments, ULT5, ULT10 and ULT15. In treatments ULT10 and ULT15 the EBF of Balady eggs was significantly reduced while the hatchability of the Balady and Leghorn eggs was significantly reduced by the ULT15 and W15 treatments, compared with the control. Orthogonal contrast (control vs. ULT) indicated that ULT exposure of eggs reduced their EBF significantly. Percentage egg weight loss, embryo weight and CHW was not affected by the treatments. It was concluded that exposure of eggs to ULT of 117 volts at $40 \mathrm{kHz}$ for 15 minutes reduced EBF and hatchability of layer-type breeder eggs without altering egg weight loss, embryo weight or CHW.
\end{abstract}

Keywords: Balady breeders, Leghorn hens, egg weight loss, embryo, hatchability

\# Corresponding author: tmshafey@ksu.edu.sa

\section{Introduction}

The handling of eggs after lay is an important factor that influences eggshell quality and consequently hatchability and chick quality (Moyle et al., 2008). The eggshell is not a solid structure, but contains pores that allow gas exchange and water to exit during embryonic growth and development. Although these pores allow the embryo to breathe, they can bring about bacterial contamination. This contamination might be carried to the embryo and other chicks during hatch, and even into the rearing stage. Fortunately, eggs have a defence mechanism that can fight most types of contamination, but not all. Sanitizing the surface of the eggshell to reduce bacterial populations has been suggested as a way of improving hatchability and chick quality. Davies \& Breslin (2003) indicated that improved sanitary processes at some farms and egg packing plants have decreased salmonellae, but did not eliminated them from the surfaces of the eggshell. Several methods such as fumigation, spray application, UV light and egg washing, and chemical agents have been developed for sanitizing hatching and table eggs (Scott \& Swetnam, 1993; Berrang et al., 2000; Wilson, 2002; Coufal et al., 2003). In addition, ultrasonic waves (ULT) have been investigated as a method of cleaning eggs and controlling pathogenic organisms (Dawson et al., 1962; Wladyka et al., 1963; Giarola et al., 1970; Sert et al., 2011; Aygun \& Sert, 2012). Heath et al. (1980) used a combination of ULT and acetic acid to clean eggs, and Slapp (1995) used a combination of ULT and a bactericide to sanitize hatching eggs. The mechanism of ULT cleaning is based on cavitation, a phenomenon produced in liquids when a ULT wave is travelling through them. Ultrasonic vibration of eggs immersed in a liquid causes a scrubbing 
action on the eggshell surface. However, when eggs are subjected to sonication in a liquid, a number of physical and mechanical effects can occur. The eggshell may undergo surface erosion or thickness reduction. Dawson et al. (1962) and Wladyka et al. (1963) found that ULT vibrations caused the cleaning solution to penetrate the eggs. ULT can trigger small, almost invisible cracks in the shell that affect eggshell characteristics such as porosity. Therefore, the effect of ULT on eggshell may be influenced by the exposure period to ULT. Recently Sert et al. (2011) found no significant difference at the first day of treatment on eggshell strength between ULT-treated eggs and the control. However, when stored for 10 days at $5{ }^{\circ} \mathrm{C}$, they found that eggshell strength of eggs treated with ULT for up to 30 minutes was higher than that of the untreated eggs.

This study was designed to investigate the effects of exposure period of ULT of 117 volts at $40 \mathrm{kHz}$ to hatching eggs before incubation, on eggshell strength, embryonic growth and hatchability.

\section{Materials and Methods}

In Trial 1 the effects were investigated of exposing layer-type breeder eggs (Balady) to ULT for up to 15 minutes before incubation, on the EBF, hatchability, hatchability failures of eggs and CHW. A total of 364 freshly laid eggs produced by a flock of 50-week-old birds were used in this trial. Eggs were candled with light to detect cracks and other defects before ULT exposure. The birds were fed a standard breeder ration (160 g CP/kg, $12 \mathrm{MJ} \mathrm{ME} / \mathrm{kg}, 34 \mathrm{~g}$ calcium, $4.5 \mathrm{~g}$ available phosphorus/kg) and reared under standard husbandry conditions. A photoperiod of $14 \mathrm{~h}$ commenced when the birds were caged at 22 weeks of age and this was maintained throughout the trials. Eggs were numbered, weighed individually, distributed into weight classes and assigned to 28 replicates of 13 eggs per replicate. Four replicates were randomly assigned to each of the seven experimental treatments. The treatments were non-dipped (control) and dipped for 5, 10 and 15 minutes in a water bath (W5, W10 and W15) or a ULT bath of 117 volts at $40 \mathrm{kHz}$ frequency (ULT5, ULT10 and ULT15) before incubation. A ULT bath (Cole-Parmer, CPN-956-252, IL, USA) filled with water was used, and the eggs were sunk and exposed to ultrasonic wave at $28{ }^{\circ} \mathrm{C}$. Eight eggs from each treatment were selected at random to investigate the effects of $\mathrm{W}$ and ULT on the breaking force of the eggshells. The eggs were individually weighed. Measurements of dimensions were taken by steel vernier calliper graduated to one tenth of a millimetre. Egg volume was calculated according to Narushin (2005):

Egg volume $=(0.6057-0.0018 \mathrm{~B}) \mathrm{LB}^{2}$

where $\mathrm{L}=$ egg length and $\mathrm{B}=$ egg width.

The surface area of the egg was estimated from the allometric relationship of Paganelli et al. (1974): area $\left(\mathrm{cm}^{2}\right)=4.835 \mathrm{~W}^{0.662}$

where $\mathrm{W}$ = initial egg weight. The EBF was determined with an egg force reader instrument (Orka Food Technology, Wanchai, Hong Kong). Measurements were made of egg weight, egg dimensions (length, width, volume and surface area), EBF, percentages of hatchability, hatchability failures (dead embryos, pips with live embryos and pips with dead embryos) and CHW (percentage chick weight at hatch = chick weight at hatch/egg weight $* 100$ ).

In Trial 2 the effects of exposure of layer-type breeder eggs (Leghorn) to ULT before incubation for up to 15 minutes on the egg weight loss, embryo weight and hatchability were investigated. A total of 240 eggs produced by hens at 53 weeks of age were used and allocated to four treatments. Husbandry conditions of the flock were similar to that for the Balady flock. The treatments were: Control (ULT0), ULT5, ULT10 and ULT15. Eggs were treated as in Trial 1 and evenly assigned to 16 replicates of 15 eggs of equal weight per each replicate. Replicates were assigned to the four treatments and incubated. Six eggs per treatment were removed for egg weight loss and embryo weight measurements on d 14, and d 18 of incubation. Eggs were weighed and broken open, and embryos were separated and weighed individually after removing the yolk sac and placing them on a paper tissue to dry. Percentages were calculated of egg weight loss (percentage egg weight loss = egg weight after incubation/egg weight before incubation*100) and embryonic weight (percentage embryo $=$ embryo weight/egg weight before incubation*100). Measurements were made of egg weight and percentages of egg weight loss, embryo weight during incubation, hatchability and hatchability failures and CHW.

Eggs were set in a Maino force-draft incubator (Model II, Maino Enrico, Co., Rome, Italy) and incubated at $99.5{ }^{\circ} \mathrm{F}\left(37.5{ }^{\circ} \mathrm{C}\right)$ and $55 \%$ relative humidity. For chick identification at hatch, the eggs were transferred to separate compartments in the hatching tray on d 19 of incubation. The hatching tray was divided into individual hatching compartments using thin sheets of wire mesh. Incubation procedures were 
similar to those published elsewhere (Shafey et al., 2012), in which eggs were examined by candling at $\mathrm{d} 6$ and d 14 of incubation. Clear eggs and eggs containing dead embryos were removed. Early-dead embryos were counted from d 1 to $\mathrm{d} 14$ of incubation. The hatcher condition was $98.6{ }^{\circ} \mathrm{F}\left(37^{\circ} \mathrm{C}\right)$ and $65 \%$ relative humidity until the end of d 21 of incubation, at which time chicks, pips (unhatched eggs with live or dead chicks) and late dead embryos (unhatched eggs with unbroken shell) were counted. Late-dead embryos were counted from d 14 to the end of $\mathrm{d} 21$, when incubation ended. Percentage hatchability was calculated on the basis of the number of hatched chicks as a per cent of the number of fertile eggs per treatment. Chicks were removed and hatching weight was recorded at the end of $21 \mathrm{~d}$ when the incubation ended.

Data on egg characteristics, EBF, hatchability and hatchability failures (Trials 1 and 2) were subjected to a one-way ANOVA. Data on egg weight loss, and embryonic weight were arranged in $4 \mathrm{x} 2$ factorials with four levels of treatments (ULT0, ULT5, ULT10 and ULT15) and two days of incubation (14 and 18 d) as main effects and their two-way interactions fitted into the model. All per cent data were transformed using arc sine square root percentage transformation before analysis. When significant variance ratios were detected, differences between treatment means were tested using the least significant difference (LSD) procedure. All statistical analyses were performed using the Statistical Analysis System (SAS, 2006).

\section{Results and Discussion}

The effects of exposing layer-type breeder eggs (Balady and Leghorn, Trials 1 and 2, respectively) to ULT of 117 volts at $40 \mathrm{kHz}$ for up to 15 minutes on EBF, hatchability, egg weight loss and embryo weight are shown in Tables 1 to 4, respectively. Exposing Balady eggs to ULT for 10 and 15 minutes significantly $(P<0.01)$ reduced EBF when compared with those of the control.

Table 1 Physical dimensions and eggshell breaking force of layer-type breeder eggs (Balady) dipped in water (W) and exposed to ultrasound (ULT) of 117 volts at $40 \mathrm{kHz}$ for up to 15 minutes before incubation $(\text { Trial } 1)^{1}$

\begin{tabular}{lcccccc}
\hline Treatment $^{2}$ & $\begin{array}{c}\text { Egg weight } \\
(\mathrm{g})\end{array}$ & $\begin{array}{c}\text { Egg length } \\
(\mathrm{mm})\end{array}$ & $\begin{array}{c}\text { Egg width } \\
(\mathrm{mm})\end{array}$ & $\begin{array}{c}\text { Egg volume } \\
\left(\mathrm{cm}^{3}\right)^{3}\end{array}$ & $\begin{array}{c}\text { Egg surface } \\
\text { area }\left(\mathrm{cm}^{2}\right)^{4}\end{array}$ & $\begin{array}{c}\text { Eggshell breaking } \\
\text { force }(\mathrm{kg})\end{array}$ \\
\hline Control & $55.1 \pm 1.31$ & $55.1 \pm 0.68$ & $42.5 \pm 0.26$ & $52.7 \pm 1.21$ & $68.7 \pm 1.07$ & $4.47^{\mathrm{a}} \pm 0.14$ \\
W5 & $54.7 \pm 1.54$ & $55.7 \pm 0.79$ & $42.7 \pm 0.35$ & $53.7 \pm 1.48$ & $68.3 \pm 1.28$ & $4.23^{\mathrm{ab}} \pm 0.28$ \\
W10 & $55.1 \pm 1.88$ & $55.2 \pm 0.74$ & $41.9 \pm 0.51$ & $51.7 \pm 1.79$ & $68.6 \pm 1.54$ & $3.93^{\mathrm{a}} \pm 0.14$ \\
W15 & $54.4 \pm 1.04$ & $54.7 \pm 0.48$ & $41.6 \pm 0.33$ & $50.3 \pm 1.06$ & $68.1 \pm 0.86$ & $4.16^{\mathrm{ab}} \pm 0.21$ \\
ULT5 & $55.5 \pm 0.34$ & $55.4 \pm 0.25$ & $42.3 \pm 0.11$ & $52.5 \pm 0.34$ & $60.1 \pm 0.28$ & $3.99^{\mathrm{ab}} \pm 0.22$ \\
ULT10 & $54.1 \pm 0.38$ & $55.0 \pm 0.28$ & $41.6 \pm 0.19$ & $50.4 \pm 0.38$ & $67.9 \pm 0.32$ & $3.72^{\mathrm{bc}} \pm 0.26$ \\
ULT15 & $55.4 \pm 1.28$ & $54.9 \pm 0.35$ & $42.0 \pm 0.40$ & $51.4 \pm 1.13$ & $69.0 \pm 1.06$ & $3.20^{\mathrm{c}} \pm 0.10$ \\
& & & & & & \\
SEM & 1.3 & 0.6 & 0.5 & 1.21 & 1.11 & 0.2 \\
$P$-value & NS & NS & NS & NS & NS & $* *$
\end{tabular}

\section{Contrast analysis of eggshell breaking force}

Control vs. All treatments

$\begin{array}{ccc}\text { Mean square } & \text { F value } & \text { Pr }>\text { F } \\ 3.53332067 & 9.92 & 0.0026 \\ 1.11444713 & 3.13 & 0.0823 \\ 5.72052023 & 16.06 & 0.0002 \\ 2.80520241 & 7.87 & 0.0069\end{array}$

Control vs. 5W \& $10 \mathrm{~W} \& 15 \mathrm{~W}$

Control vs. 5ULT \& 10 ULT \& 15ULT

5W \& 10W \& 15 vs. 5ULT \& 10ULT \& 15ULT

\footnotetext{
${ }^{1}$ Values are means \pm SE of eight eggs.

2 The treatments were non-dipped control and dipped for 5, 10 and 15 minutes in water bath (W5, W10 and W15) or ULT bath of 117 volts at $40 \mathrm{kHz}$ frequency (ULT5, ULT10 and ULT15) before incubation.

${ }^{3}$ The egg volume was calculated from Narushin $(2005)=(0.6057-0.0018 B) \mathrm{LB}^{2}$, where $\mathrm{L}=$ length, $\mathrm{B}=$ width of the egg.

${ }^{4}$ Egg surface area was calculated from Paganelli et al. $(1974)=4.84 \mathrm{~W}^{0.662}$, where $\mathrm{W}=$ egg weight.

** Significantly different $(P<0.01)$; NS: not significant $(P>0.05)$.
} 
Table 2 Mean per cent of hatchability, hatchability failures and chick hatching weight expressed on an absolute and percentage basis (chick hatching weight*100/egg weight) of layer-type breeder eggs (Balady) dipped in water (W) and exposed to ultrasound (ULT) of 117 volts at $40 \mathrm{kHz}$ for up to 15 minutes before incubation (Trial 1$)^{1}$

\begin{tabular}{|c|c|c|c|c|c|c|c|c|}
\hline Treatment $^{2}$ & $\begin{array}{c}\text { Hatch of } \\
\text { fertile eggs } \\
(\%) \\
\end{array}$ & $\begin{array}{c}\text { Early dead } \\
\text { embryos } \\
(\%) \\
\end{array}$ & $\begin{array}{c}\text { Late dead } \\
\text { embryos } \\
(\%) \\
\end{array}$ & $\begin{array}{c}\text { Pipped with } \\
\text { live embryos } \\
(\%)\end{array}$ & $\begin{array}{c}\text { Pipped with } \\
\text { dead embryos } \\
(\%)\end{array}$ & $\begin{array}{l}\text { Egg weight } \\
\text { (g) }\end{array}$ & $\begin{array}{c}\text { Chick weight } \\
\text { (g) }\end{array}$ & $\begin{array}{c}\text { Chick weigh } \\
\text { (\%) }\end{array}$ \\
\hline Control & $93.8^{\mathrm{a}} \pm 4.09$ & $0.00^{\mathrm{b}} \pm 0.00$ & $6.25 \pm 4.09$ & $0.00 \pm 0.00$ & $0.00 \pm 0.00$ & $52.6 \pm 0.96$ & $36.4 \pm 0.79$ & $67.2 \pm 0.89$ \\
\hline W5 & $90.6^{\mathrm{a}} \pm 4.57$ & $0.00^{\mathrm{b}} \pm 0.00$ & $9.37 \pm 4.27$ & $0.00 \pm 0.00$ & $0.00 \pm 0.00$ & $52.0 \pm 1.28$ & $34.5 \pm 1.12$ & $66.4 \pm 1.34$ \\
\hline W10 & $80.0^{\mathrm{ab}} \pm 7.56$ & $10.00^{\mathrm{a}} \pm 3.78$ & $10.00 \pm 3.78$ & $0.00 \pm 0.00$ & $0.00 \pm 0.00$ & $52.3 \pm 0.97$ & $34.6 \pm 0.84$ & $66.2 \pm 1.36$ \\
\hline W15 & $73.6^{\mathrm{bc}} \pm 3.10$ & $13.50^{\mathrm{a}} \pm 4.13$ & $9.00 \pm 2.90$ & $2.25 \pm 1.48$ & $1.50 \pm 1.50$ & $51.7 \pm 0.98$ & $34.2 \pm 0.78$ & $66.3 \pm 0.96$ \\
\hline ULT5 & $95.0^{\mathrm{a}} \pm 3.27$ & $0.00^{\mathrm{b}} \pm 0.00$ & $5.00 \pm 3.27$ & $0.00 \pm 0.00$ & $0.00 \pm 0.00$ & $53.0 \pm 0.97$ & $35.9 \pm 0.68$ & $67.8 \pm 0.64$ \\
\hline ULT10 & $83.8^{\mathrm{abc}} \pm 3.63$ & $7.00^{\mathrm{ab}} \pm 3.09$ & $7.00 \pm 3.99$ & $0.75 \pm 0.75$ & $1.50 \pm 1.50$ & $52.2 \pm 0.96$ & $34.8 \pm 0.61$ & $66.8 \pm 0.83$ \\
\hline ULT15 & $77.5^{c} \pm 5.43$ & $8.25^{\mathrm{a}} \pm 3.88$ & $12.25 \pm 4.69$ & $2.00 \pm 1.36$ & $0.00 \pm 0.00$ & $51.4 \pm 0.95$ & $34.5 \pm 1.02$ & $66.8 \pm 0.83$ \\
\hline SEM & 4.9 & 2.75 & 3.92 & 0.86 & 0.81 & 1.02 & 0.84 & 0.99 \\
\hline$P$-value & $* *$ & $* *$ & NS & NS & NS & NS & NS & NS \\
\hline
\end{tabular}

${ }^{1}$ Values are means \pm SE.

${ }^{2}$ The treatments were non-dipped control and dipped for 5, 10 and 15 minutes in a water bath (W5, W10 and W15) or ULT bath of 117 volts at 40 kHz frequency (ULT5, ULT10 and ULT15) before incubation.

a,b,c Means within column followed by different superscripts are significantly different $(P<0.05)$; $\quad$ NS: not significant $(P>0.05)$. 
Table 3 Mean per cent of egg weight loss and embryo weight of layer-type breeder eggs (Leghorn) exposed to ultrasound (ULT) of 117 volts at $40 \mathrm{kHz}$ for up to 15 minutes before incubation (Trial 2)

\begin{tabular}{|c|c|c|c|}
\hline $\begin{array}{c}\text { Treatment }(\mathrm{T})^{2} \\
\text { (minutes) }\end{array}$ & $\begin{array}{l}\text { Egg weight } \\
\text { (g) }\end{array}$ & $\begin{array}{c}\text { Egg weight loss }{ }^{2} \\
(\%)^{3}\end{array}$ & $\begin{array}{c}\text { Embryo weight } \\
(\%)^{3}\end{array}$ \\
\hline ULT0 & $58.8 \pm 2.28$ & $9.1 \pm 0.76$ & $31.8 \pm 3.37$ \\
\hline ULT5 & $56.7 \pm 1.73$ & $9.6 \pm 0.54$ & $31.0 \pm 3.35$ \\
\hline ULT10 & $59.2 \pm 1.00$ & $9.1 \pm 0.65$ & $32.2 \pm 3.76$ \\
\hline ULT15 & $57.8 \pm 1.51$ & $9.4 \pm 0.59$ & $32.6 \pm 3.90$ \\
\hline \multicolumn{4}{|l|}{ Embryo age (day) } \\
\hline 14 & $57.8 \pm 0.85$ & $7.6^{\mathrm{b}} \pm 0.18$ & $20.3^{\mathrm{b}} \pm 0.42$ \\
\hline 18 & $58.5 \pm 1.15$ & $11.1^{\mathrm{a}} \pm 0.23$ & $43.5^{\mathrm{a}} \pm 0.61$ \\
\hline SEM & 1.25 & 0.25 & 0.59 \\
\hline \multicolumn{4}{|l|}{ Interaction } \\
\hline Treat & NS & NS & NS \\
\hline Embryo age & NS & $* *$ & $* *$ \\
\hline Treat x embryo age & NS & NS & NS \\
\hline \multicolumn{4}{|c|}{$\begin{array}{l}{ }^{1} \text { Values are means } \pm \text { SE. } \\
2 \text { The treatments were control (non-exposed to ULT) or exposed to ULT for } 5,10 \text { and } 15 \\
\text { minutes (ULT0, ULT5, ULT10 and ULT15) before incubation. } \\
{ }^{3} \text { As a percentage of egg weight. } \\
\text { a,b,c Means within column followed by different superscripts are significantly different }(P<0.05) \text {; } \\
\text { NS: not significant }(P>0.05) \text {. }\end{array}$} \\
\hline
\end{tabular}

An orthogonal contrast test indicated a trend in the reduction in the strength of eggshell with increasing the period of exposing eggs to ULT $(P<0.06, P<0.01$ and $P<0.01$ for control vs. ULT5, control vs. ULT5 and control vs. ULT15, respectively, results are not shown). The eggshells exposed to ULT had a lower strength than those not dipped or dipped in water $(P<0.01$, Table 1$)$. This finding may suggest that exposing eggs to ULT of 117 volts at $40 \mathrm{kHz}$ for 10 and 15 minutes influenced the quality of eggshell. The intention of using ULT is to remove dirt and microorganisms on the surface of the eggshell. However, it seems that the constant bombarding of the inrush fluid during sonication influenced the quality of eggshell and consequently EBF. Eggs used in this study were candled to detect cracks and other defects and have similar characteristics. There was no difference in the weight or physical dimension of eggs among treatments (egg length, egg width and egg volume size or egg surface area). The strength of an eggshell is determined not just by the amount of shell that is present, but also by the relationship between shell components (Bain, 2005; Fathi et al., 2007) and the quality of structure of the shell (Roberts, 2010). Eggshell is the first defence barrier; a damaged eggshell may facilitate the entry of microorganisms into the egg resulting in an increase in embryonic mortality.

The ULT15 treatment reduced $(P<0.05)$ hatchability of Balady and Leghorn eggs when compared with those of the control (Tables 2 and 4, respectively). The negative effect of low eggshell quality on hatchability has been reported in several studies (Narushin \& Romanov, 2002; Barnett et al., 2004; Wolc et al., 2010). The reduction in hatchability of Balady eggs exposed to ULT15 was associated with a significant increase in early-dead embryos and a non-significant increase in late-dead embryos (Trial 1). The reduction in hatchability of Leghorn eggs was associated with a significant increase in early-dead embryos and non-significant increase in early- and dead-embryos and pipped with live and dead embryos (Trial 2). The slight difference in hatchability failures of eggs exposed to ULT15 between the two trials is probably related to differences in eggshell characteristics of the genetic make-ups of the two types of bird. Shafey (2002) showed that genetic make-up of birds and size of the egg influenced eggshell characteristics and hatchability of eggs. Genetic differences in eggshell quality have been shown to influence eggshell 
Table 4 Mean per cent of hatchability, hatchability failures, egg weight and chick hatching weight express on an absolute and percentage basis (chick hatching weight*100/egg weight) of layer-type breeder eggs (Leghorn) exposed to ultrasound (ULT) of 117 volts at $40 \mathrm{kHz}$ for up to $15 \mathrm{minutes}$ before incubation (Trial 2)

\begin{tabular}{|c|c|c|c|c|c|c|c|c|}
\hline Treatment $^{2}$ & $\begin{array}{c}\text { Hatch of } \\
\text { fertile eggs } \\
(\%)^{2} \\
\end{array}$ & $\begin{array}{c}\text { Early dead } \\
\text { embryos } \\
(\%) \\
\end{array}$ & $\begin{array}{c}\text { Late dead } \\
\text { embryos } \\
(\%) \\
\end{array}$ & $\begin{array}{c}\text { Pipped with } \\
\text { live embryos } \\
(\%)\end{array}$ & $\begin{array}{c}\text { Pipped with } \\
\text { dead embryos } \\
(\%)\end{array}$ & $\begin{array}{l}\text { Egg weight } \\
\text { (g) }\end{array}$ & $\begin{array}{c}\text { Chick weight } \\
\text { (g) }\end{array}$ & $\begin{array}{c}\text { Chick weight } \\
\text { (\%) }\end{array}$ \\
\hline ULT0 & $89.3^{\mathrm{a}} \pm 2.10$ & $7.68 \pm 1.53$ & $3.03 \pm 1.82$ & $0.00 \pm 00.00$ & $0.00 \pm 00.00$ & $58.5 \pm 0.61$ & $42.2 \pm 0.47$ & $72.2 \pm 0.44$ \\
\hline ULT5 & $85.2^{\mathrm{ab}} \pm 2.80$ & $10.96 \pm 2.65$ & $3.85 \pm 1.20$ & $0.00 \pm 00.00$ & $0.00 \pm 00.00$ & $58.4 \pm 0.57$ & $42.1 \pm 0.45$ & $72.0 \pm 0.26$ \\
\hline ULT10 & $84.9^{\mathrm{ab}} \pm 2.11$ & $9.09 \pm 1.89$ & $3.77 \pm 1.69$ & $2.22 \pm 1.50$ & $0.00 \pm 00.00$ & $58.8 \pm 0.62$ & $42.3 \pm 0.55$ & $71.9 \pm 0.30$ \\
\hline ULT15 & $82.4^{\mathrm{b}} \pm 1.16$ & $10.03 \pm 1.92$ & $5.10 \pm 1.72$ & $1.28 \pm 1.05$ & $1.19 \pm 00.00$ & $58.5 \pm 0.76$ & $42.2 \pm 0.63$ & $72.1 \pm 0.28$ \\
\hline SEM & 2.12 & 2.07 & 1.38 & 0.86 & 0.40 & 0.66 & 0.54 & 0.33 \\
\hline$P$-value & $* *$ & NS & NS & NS & NS & NS & NS & NS \\
\hline
\end{tabular}

${ }^{1}$ Values are means $\pm \mathrm{SE}$.

${ }^{2}$ There was no significant difference in the percentage of fertile eggs (mean \pm SE) between treatments $(93.8 \pm 1.44,94.7 \pm 0.86,94.6 \pm 1.57,95.8 \pm 1.25$ and $93.79 \pm$

1.92 for control (non-exposed to ULT) and those exposed to ULT for 5, 10 and 15 minutes (ULT0, ULT5, ULT10 and ULT15) before incubation.

${ }^{\mathrm{a}, \mathrm{b}}$ Means within column followed by different superscripts are significantly different $(P<0.05)$. 
conductance (Christensen et al., 1995). Leghorn eggs were heavier by approximately $12 \%$ in comparison with Balady eggs (52.2 g and $58.2 \mathrm{~g}$ for Balady and Leghorn, respectively). Large eggs have a proportionally lower surface area to volume ratio than small eggs (Marshall \& Cruickshank, 1938). Selection of large turkeys has altered eggshell conductance (Christensen \& McCorkle, 1982) and pore arrangements on the eggshell (Christensen, 1983).

Results from egg weight loss, embryo weight and CHW (Tables 2, 3 and 4) indicate that ULT of 117 volts at $40 \mathrm{kHz}$ of eggs for up to 15 minutes before incubation did not significantly influence relative egg weight loss, embryonic weight or CHW. In addition, there was no significant difference in embryo weight among treatments. The possible reason for these findings is that weak embryos died during the incubation process, and the remaining embryos were similar in weight. These results suggest that ULT did not influence the rate of water loss from the egg and consequently eggshell porosity and embryonic development (Narushin \& Romanov, 2002). Egg weight loss during incubation serves as an indication of overall porosity of eggshell (Peebles et al., 1998). These results are in agreement with Levenick et al. (1975) who reported that exposing incubating embryos to short ULT pulses of $2.25 \mathrm{MHz}$ for three minutes across the intact eggshell did not influence embryonic mutation, hatchability, sex ratio or body weight. Also, Aygun \& Sert (2012) reported that exposing Japanese quail eggs to ULT of $35 \mathrm{kHz}$ for ULT to 15 minutes did not influence egg weight loss. Vazquez (1963) reported that exposing eggs across the intact shell at 26 - 52 hours of incubation to $0.87 \mathrm{MHz}$ at $0.5-3 \mathrm{~W} / \mathrm{cm}^{2}$ intensities for up to 30 minutes did not produce any embryonic abnormality. However, when embryos were exposed directly to ULT, a high percentage of abnormally developed embryos was produced. Similarly, Roncari \& Tomlinson (1968) claimed that exposing 1- to 3day-old embryos to ULT pulse frequencies of $0.5,2.25$ or $5 \mathrm{MHz}$ across the shell for up to 165 seconds could cause permanent genetic changes. However, Vazquez (1963) proposed that the shell obstructs penetration of ULT waves. This finding may suggest that the reduction in eggshell strength caused by the ULT10 and ULT15 treatments was not to the extent to affect egg weight loss or embryonic growth.

While the literature suggests beneficial effects when using ULT in sanitizing hatching eggs, some negative effects were recorded. This present study revealed that ULT of 117 volts at $40 \mathrm{kHz}$ for 10 and 15 minutes reduced eggshell strength and ULT for 15 minutes reduced hatchability of layer-type breeder eggs without affecting egg weight loss, embryonic growth or CHW. Further studies are required to investigate the effects of ULT on the ultrastructure of the shell before scientists can confirm whether ULT is harmful to the quality and structure of the eggshell or not.

\section{Acknowledgements}

The authors extend their appreciation to the Deanship of Scientific Research at King Saud University for funding the work through the Research Group Project No RGP-VPP-185.

\section{Reference}

Aygun, A. \& Sert, D., 2012. Effects of ultrasonic treatment on eggshell microbial activity, hatchability, tibia mineral content, and chick performance in Japanese quail (Coturnix coturnix japonica) eggs. Poult. Sci. 91, 732-738.

Bain, M.M., 2005. Recent advances in the assessment of eggshell quality and their future application. Wrld's Poult. Sci. J. 61, 268-277.

Barnett, D.M., Kumpula, B.L., Petryk, R.L., Robinson, N.A., Renema, R.A. \& Robinson, F.E., 2004. Hatchability and early chick growth potential of broiler breeder eggs with hairline cracks. J. Appl. Poult. Res. 13, 65-70.

Berrang, M.E., Buhrand, R.J. \& Cason, J.A., 2000. Campylobacter recovery from external and internal organs of commercial broiler carcass prior to scalding. Poult. Sci. 79, 286-290.

Christensen, V.L., 1983. Distribution of pores on hatching and nonhatching turkey eggs. Poult. Sci. 62, 1312-1316.

Christensen, V.L. \& McCorkle, F.M., 1982. Turkey egg weight losses and embryonic mortality during incubation. Poult. Sci. 61, 1209-1213.

Christensen, V.L., Havenstein, G.B. \& Davis, G.S., 1995. Egg characteristics, carbohydrate metabolism, and thyroid hormones in late chick embryos from different genetic lines. Poult. Sci. 74, 551-562.

Coufal, C.D., Chavez, C., Knape, K.D. \& Carey, J.B., 2003. Evaluation of a method of ultraviolet light sanitation of broiler hatching eggs. Poult. Sci. 82, 754-759. 
Davies, R.H. \& Breslin, M., 2003. Investigation of Salmonella contamination and disinfection in farm egg packing plants. J. Appl. Microbiol. 94, 191-196.

Dawson, I.E., Hall, C.E., Farmer, E.H. \& Mallmann, W.L., 1962. The use of ultrasonic energy for cleaning eggs. Poult. Sci. 41, 620-626.

Fathi, M.M., Zein El-Dein, A., El-Safty, S.A. \& Radwan, L.M., 2007. Using scanning electron microscopy to detect the ultrastructural variations in eggshell quality of Fayoumi and Dandarawi chicken breeds. Int. J. Poult. Sci. 6, 236-241.

Giarola, A.J., Kruegerand, W.F. \& Hansen, C.N., 1970. Cleaning egg shell with ultrasound. Poult. Sci. 49, 1387-1395.

Heath, J.L., Owens, S.L. \& Goble, J.W., 1980. Ultrasonic vibration as an aid in the acetic acid method of cleaning eggs. Poult. Sci. 59, 737-742.

Levenick, C.K., Kondra, P.A. \& Freese, M., 1975. Exposure of eggs to ultrasound during incubation and its effect on hatchability and growth. Poult. Sci. 54, 369-373.

Marshall, W. \& Cruickshank, D.B., 1938. The function of the cuticle in relation to the porosity of eggs. J. Agric. Sci. 28, 24-42.

Moyle, J.R., Yoho, D.E., Harper, R.S., Swaffar, A.D., Bramwell, R.K. \& Elfick, D.J., 2008. Egg shell color, specific gravity and hatchability, in eggs from broiler breeders. Poult. Sci. 87 (Suppl.1), 146.

Narushin, V.G., 2005. Egg geometry calculation using themeasurements of length and breadth. Poult. Sci. J. 84, $482-484$.

Narushin, V.G. \& Romanov, M.N., 2002. Egg physical characteristics and hatchability. Wrld's Poult. Sci. J. 58, 297-303.

Paganelli, C.V., Olszowka, A. \& Ar, A., 1974. The avian egg surface area, volume, and density. Condor 76, 319-325.

Peebles, E.D., Pansky, T., Doyle, S.M., Boyle, C.R., Smith, T.W., Latour, M.A. \& Gerard, P.D., 1998. Effects of dietary fat and eggshell cuticle removal on egg water loss and embryo growth in broiler hatching eggs. Poult. Sci. 77, 1522-1530.

Roberts, J.R., 2010. Factors affecting egg shell quality and egg internal quality. 18th Annual ASAIM SE Asian Feed Technology and Nutrition Workshop, May 24-27, Le Meridien Siem Reap, Cambodia.

Roncari, A.J. \& Tomlinson, R.H., 1968. Method of producing a specific genetic effect resulting in a larger and earlier maturing domestic fowl. United States Patent No. 3, 382, 846.

SAS, 2006. Statistical analysis System, 2006. SAS Institute Inc, Cary, N.C., USA.

Scott, T.A. \& Swetnam, C., 1993. Screening sanitizing agents and methods of application for hatching eggs I. Environmental and user friendliness. J. Appl. Poult. Res. 2, 1-6.

Sert, D., Aygun, A. \& Demir, M.K., 2011. Effects of ultrasonic treatment and storage temperature on egg quality. Poult. Sci. 90, 869-875.

Shafey, T.M., 2002. Effect of egg size and eggshell conductance on hatchability traits of meat and layer breeder flocks. A.J.A.S. 15, 1-6.

Shafey, T.M., Alodan, M.A., Al-Ruqaie, I.M. \& Abouheif, M.A., 2012. In ovo feeding of carbohydrates and incubated at a high incubation temperature on hatchability and glycogen status of chicks. S. Afr. J. Anim. Sci. 42, 210-220.

Slapp, P., 1995. Production line cleaning. UK British Patent 95005872.

Vazquez, C.S., 1963. Cephalic changes in chick embryos under the action of ultrasound. Annals Oto. Rhin. and Laryng. 72, 103-112.

Wilson, H.R., 2002. Hatching egg sanitation. IFAS, University of Florida, USA.

Wladyka, E.J., Dawson, L.E. \& Walker, R.W., 1963. The influence of ultrasonic treatment of egg quality. Poult. Sci. 42, 1154-1161.

Wolc, A., White, I.M.S., Hill, W.G. \& Olori, V.E., 2010. Inheritance of hatchability in broiler chickens and its relationship to egg quality traits. Poult. Sci. 89, 2334-2340. 